\title{
Repercussões da violência intrafamiliar: Um estudo com mulheres em acompanhamento psicológico
}

\author{
Repercussions of intrafamily violence: A study with women undergoing psychotherapy
}

Jólia Schneider Hermel[a], Luciana Balestrin Redivo Drehmer ${ }^{[b]}$

[a] Psicóloga, especialista em Saúde da Família e Comunidade pelo Programa de Residência Multiprofissional em Saúde da Família e Comunidade (Premus) da Pontifícia Universidade Católica do Rio Grande Sul (PUCRS), mestranda em Psicologia Social na mesma instituição, Porto Alegre, RS Brasil, e-mail: juliahermel@yahoo.com.br

${ }^{[b]}$ Psicóloga, psicanalista, mestre em Psicologia Clínica pela Pontifícia Universidade Católica do Rio Grande do Sul (PUCRS), professora da Faculdade de Psicologia da mesma instituição, Porto Alegre, RS - Brasil, e-mail: luciana.redivo@pucrs.br

Recebido: 06/10/2011 Received: 10/06/2011

Aprovado: 09/04/2012 Approved: 04/09/2012

\begin{abstract}
Resumo
O presente estudo objetivou conhecer o significado e as repercussões da experiência de violência de mulheres que tiveram acompanhamento psicológico em duas unidades de saúde do município de Porto Alegre (RS). 0 método teve delineamento qualitativo, exploratório e retrospectivo por meio de estudo de casos múltiplos. Participaram do estudo quatro mulheres submetidas à técnica de psicoterapia de apoio pela Psicologia do Programa de Residência Multiprofissional em Saúde da Família e Comunidade da Pontifícia Universidade Católica do Rio Grande do Sul. Os dados foram coletados em relatos de casos, genogramas e prontuário da família. Os resultados mostram que a demanda da violência não foi o motivo principal da busca por atendimento psicológico. As situações de violência foram reveladas ao longo do tratamento, sendo todas do tipo intrafamiliar com início na infância. Observou-se a ausência de um significado subjetivo da experiência de violência e a horizontalidade da violência na vida. A principal repercussão subjetiva percebida nas mulheres estudadas é a perpetuação da violência nas relações atuais
\end{abstract}

Palavras-chave: Violência. Saúde da família. Psicoterapia. Atenção primária à saúde.

\begin{abstract}
The purpose of this study was to understand the meaning and repercussions of violent experiences lived by women. The women studied underwent psychotherapy in two primary health care units in the city of Porto Alegre. This multiple case study was of a qualitative, exploratory, and retrospective nature. The study's participants were four women treated using supportive psychotherapy by the Pontifícal Catholic University of Rio Grande do Sul Family and Community Health Multiprofessional Residency Program. Data was collected from case reports, genograms, and family records. The study's results show that violent experiences were not the main reason for seeking psychological care. The individual events that constituted these violent experiences were revealed progressively through therapy. All reported events were domestic and first occurring in childhood. The absence of an attributed subjective meaning to the violent experience was observed, along with the horizontality of violence in the participants' lives. The main subjective repercussion perceived by the participants was the perpetuation of violence in their current relationships.
\end{abstract}

Keywords: Violence. Family health. Psychotherapy. Primary health care.

Psicol. Argum. 2013 jul./set., 31 (74), 437-446 


\section{Introdução}

A violência é um fenômeno sócio-histórico, de compreensões múltiplas e complexas que entrou aos poucos na pauta do setor Saúde. Com o viés da saúde, o tema da violência passou a ser amplamente discutido no âmbito teórico e prático, levando a Organização Mundial da Saúde (OMS) a construir o Relatório Mundial da Violência e Saúde. Este descreve a violência como um dos principais problemas de saúde no mundo, sendo necessários programas de prevenção e maior reconhecimento na Saúde Pública (OMS, 2002). Além disso, alerta-se sobre a violência que é considerada "invisível" - não resultante em lesões graves ou morte - e que normalmente ocorre nos lares das famílias, nas instituições de trabalho e até mesmo nos serviços que deveriam cuidar das pessoas (OMS, 2002; Schraiber, D’Oliveira \& Couto, 2006).

As pesquisas de revisão bibliográfica e as realizadas em serviços de atendimentos a vítimas de violência trazem alguns dados sobre a tipologia e a natureza dos atos violentos registrados. Na revisão de 48 artigos nacionais sobre prevenção à violência contra crianças e adolescentes, Gomes, Silva e Njaine (1999) sinalizaram o predomínio da violência intrafamiliar (25\%) somados a $10 \%$ de registros de casos de natureza de abuso sexual que na maioria das vezes são perpetrados por familiares. Na revisão de Schraiber et al. (2006), que analisaram a produção brasileira sobre violência e saúde de 1980 a 2005, identificou-se grande número de pesquisas na área da violência interpessoal com detalhamentos de homicídios e também na violência intrafamiliar principalmente estudos de violência contra mulher, crianças e adolescentes e em menor número, contra idosos. As autoras ainda esclarecem que a maioria das pesquisas de violência contra mulher são realizadas em unidades básicas de saúde, hospitais e emergências, todas no âmbito do Sistema Único de Saúde (SUS).

No estudo de Milani e Loureiro (2008) sobre as notificações no Conselho Tutelar de violência sofrida por crianças e adolescentes, ressalta-se a violência do tipo doméstica como de maior prevalência e de natureza destaca-se a negligência seguida da violência física e psicológica. Outra investigação relevante sobre violência contra crianças e adolescentes traz o desfecho dos casos notificados em uma Vara da Infância e Juventude do Paraná mostrando que $40,4 \%$ dos casos encaminhados são de violência física, 30\% de negligência, $26,9 \%$ de violência sexual e 2,6\% de trabalho infantil e mendicância (Martins \& Mello Jorge, 2009). A constatação da violência física contra crianças e adolescentes também tem a maior porcentagem na pesquisa de Gomes, Almeida, Ecteins, Solter, e Paiva (1999) que ainda revela o tipo intrafamiliar, uma vez que a maioria dos agressores foram identificados como pai, mãe ou padrasto.

Considera-se a família um grupo de pessoas com vínculos afetivos, de consanguinidade ou de convivência que formam um sistema de relações, tendo como uma das funções primordiais apoiar o desenvolvimento de seus membros, promovendo crescimento e independência (Ríos, 1991). Para que as relações dentro do microssistema familiar sejam saudáveis é preciso ter estabilidade, reciprocidade e equilíbrio do poder entre os membros. A família é considerada um microssistema, já que ela possui um padrão de funcionamento, de papéis e de relacionamentos que estão associados aos comportamentos e às interações em determinados contextos. 0 microssistema está inserido em sistemas de maior amplitude como o mesossistema, o exossistema e o macrossistema, nos quais ele influencia e sofre influências (Bronfenbrenner, 1996). Segundo De Antoni e Koller (2000), a valorização ou não da família, a criação de políticas públicas de prevenção à violência são representações do macrossistema que influenciam o desenvolvimento do microssistema familiar.

Baseado nesse referencial, tem-se a família como um sistema integrado que opera para manter o equilíbrio nos diferentes contextos nos quais ela se insere. Com isso, espera-se que o indivíduo encontre na família condições para subsidiar seu desenvolvimento saudável. Contudo, essa ideia tem sido contraposta pela dimensão e pelos problemas cada vez maiores da violência intrafamiliar, considerada pelo Ministério da Saúde de caráter endêmico (Brasil, 2002).

Uma família que não está organizada para lidar com problemas ou eventos estressores não consegue buscar os recursos em si e nos sistemas mais amplos. Quando uma família não consegue compreender e superar uma crise, "os conflitos tendem a se tornar violentos" (Brasil, 2002, p. 14).

A OMS utiliza o marco ecológico de Bronfenbrenner (1996) para entender a violência na sua complexidade, na interação dos fatores individuais, relacionais, culturais, sociais e ambientais. Considera-se difícil isolar os fatores de risco que geram processos violentos; contudo, a OMS cita alguns fatores que podem aumentar os níveis de 
violência como pobreza, gênero, isolamento social, uso de drogas, acesso a armas de fogo e ausência de políticas públicas integradoras.

Assim como esses riscos, os tipos de violência também se sobrepõem e por isso é necessário lidar com a violência nos diferentes sistemas do modelo ecológico para realizar intervenção que visam prevenir a violência (OMS, 2002). Reichenheim, Hasselmann e Moraes (1999) levantam a possibilidade do ato violento dirigido a um membro da família ter efeitos indiretos e marcantes nos demais membros; como exemplo ele questiona a capacidade de uma mulher vítima de violência se relacionar e cuidar de seus filhos. Outros estudos observam a ocorrência paralela de violência intrafamiliar contra a criança e a mulher (Milani \& Loureiro, 2008).

A literatura evidencia que o impacto da violência para os indivíduos pode estar relacionado com a natureza da agressão, sua duração e intensidade, com o vínculo afetivo entre vítima e agressor, com a capacidade emocional da vítima, sua rede de apoio e a garantia do término da violência. Suas consequências emocionais são de difícil identificação, mas geralmente são representadas por sintomas como: ansiedade, depressão, transtornos psicossomáticos, dificuldade de relacionamento, comportamento agressivo, timidez, isolamento social, distúrbios do sono e do apetite, problemas no trabalho ou escola com dificuldades do desenvolvimento social e intelectual (Furniss, 2001).

Como proposta de enfrentamento e superação da violência, muitos autores sugerem um trabalho interdisciplinar e inter-setorial abordando a violência na sua própria complexidade, tanto para promoção e prevenção como para diagnóstico e tratamento das vítimas (Gomes, Almeida et al., 1999; Gomes, Silva e Njaine, 1999; Martins \& Mello Jorge, 2009; Minayo, 2006; Moura \& Reichenheim, 2005; Reichenheim et al., 1999). Além isso, percebe-se a dificuldade dos serviços para acolherem situações de violência. Segundo estudo de Moura e Reichenheim (2005), os serviços de saúde perdem oportunidades de detectar a violência domésticam a qual passa e ser, então, subdimensionada. Os autores explicam que isso ocorre porque as consultas de rotina de um serviço observam sinais e sintomas clínicos evidentes, diagnosticando situações graves, mas a violência íntima dificilmente é identificada. Outros aspectos que levam à subnotificação da violência e ao baixo índice de encaminhamentos estão relacionados à formação dos profissionais da saúde, às práticas curativas do modelo de saúde biomédico, à falta de avaliação ampliada para queixas vagas, à percepção de falta de rede de recursos e apoio para oferecer, entre outros (Moura \& Reichenheim, 2005).

$\mathrm{Na}$ área da saúde mental, verificam-se estudos que apresentam dados sobre a violência, sintomas apresentados pelos usuários e aspectos importantes do processo psicoterápico. 0 trabalho de Sant'Anna e Baima (2008) com mulheres vítimas de abuso sexual na infância ou na adolescência em psicoterapia mostra que a maioria não contou nem pediu ajuda de outras pessoas, sendo o segredo revelado pela primeira vez na psicoterapia. Furniss (2001) explica que essa "Síndrome do Secretismo" é frequente nos casos de abusos sexual, principalmente se ocorrido dentro da família. A manutenção desse segredo pode intensificar os sintomas característicos e não permite que a pessoa tenha o atendimento que necessita. No referido estudo de Sant'Anna e Baima (2008) verificou-se que os usuários chegaram à psicoterapia por outras demandas e o abuso não foi a queixa inicial. Em $89 \%$ dos casos os usuários o relataram como um acontecimento entre outros na história de vida. Ainda, 77\% dos usuários somente revelaram o abuso na fase intermediária do tratamento, o que indica a importância do vínculo para trabalhar esse tema. Os resultados dessa pesquisa também sugerem a importância da psicoterapia para diminuição dos sintomas, já que a grande parte da amostra teve melhora dos sintomas iniciais de medo, culpa, ansiedade, depressão, baixa autoestima, insegurança e ideações suicidas.

Além da importância do tratamento psicológico para as pessoas que sofreram violência intrafamiliar, preocupa-se atualmente com o envolvimento do agressor no tratamento, principalmente quando entende-se a violência como um fenômeno dinâmico, relacional e familiar, por muitas vezes transgeracional (Meneghel, Camargo \& Fasolo, 2000). No estudo de Padovani e Williams (2002) utiliza-se o recurso do atendimento psicológico dirigido ao agressor concluindo a redução do comportamento violento do marido à esposa. No trabalho que mostra a trajetória de uma casa de apoio, as autoras compreendem a violência além da dicotomia vítima e agressor. Explicam que as mulheres abrigadas reproduziam a violência dentro da instituição, seja entre elas, com os funcionários e no espaço coletivo. Esse fenômeno clareia a importância de trabalhar o padrão de funcionamento da família violenta (Meneghel, Camargo e Fasolo, 2000). 
É na dimensão dos eventos violentos não fatais, subnotificados e com subestimativas que geralmente a violência encontra-se com a Atenção Primária à Saúde. Para fazer essa reflexão, a OMS entende a natureza multifacetada da violência como resultante da interação dos fatores individuais, relacionais, culturais, sociais e ambientais (OMS, 2002; Bronfenbrenner, 1996).

Com base nesses aspectos e com o referencial do Modelo Ecológico, a questão da violência é problematizada pela primeira autora, psicóloga residente que durante trabalho de acompanhamento psicológico no Programa de Residência Multiprofissional em Saúde da Família e Comunidade (Premus/PUCRS) observou o tema da violência como emergente do discurso de grande parte dos usuários do programa. É válido ressaltar que o Premus tem uma equipe formada por profissionais de sete áreas da saúde: Enfermagem, Odontologia, Farmácia, Fisioterapia, Nutrição, Odontologia, Psicologia e Serviço Social. o Premus atua de forma interdisciplinar em unidades básicas de saúde inseridas em contextos de vulnerabilidade no Distrito Sanitário Leste/Nordeste de Porto Alegre (RS). Assim, os casos foram analisados e discutidos pela equipe e, por vezes, atendidos em interconsulta com as outras áreas. Essa forma de trabalho que compreende a atenção integral à saúde se reforçou no entendimento do usuário mesmo durante o acompanhamento psicológico individual.

Dessa forma, entendendo a violência como algo que pode ou não ser reconhecido em si pelas participantes, objetivou-se conhecer a significação atribuída à experiência de violência em usuárias que tiveram acompanhamento psicológico, além de identificar se a busca por atendimento psicológico está relacionada à experiência de violência e analisar os possíveis desfechos subjetivos para os casos atendidos. Ainda, este estudo tem como objetivo compreender as repercussões da violência na qualidade dos vínculos intrafamiliares estabelecidos pelo usuário de acordo com o genograma.

\section{Método}

Com o foco da temática da violência, esse estudo realizou-se por meio de um delineamento qualitativo, exploratório e retrospectivo de estudo de casos múltiplos para aprofundamento e detalhamento de poucos casos (Yin, 2001).
Participaram do estudo quatro mulheres com no mínimo cinco atendimentos psicológicos no Premus em Unidades de Saúde do Município de Porto Alegre (RS) durante o período de novembro de 2009 a janeiro de 2011. As participantes foram selecionadas por serem casos do tipo violência intrafamiliar e por não terem recebido o atendimento na rede de saúde mental. Dessa forma, cada uma tem suas especificidades sendo possível encontrar resultados semelhantes ou contrastantes por razões previstas na teoria (Yin, 2001).

Os instrumentos utilizados para a coleta de dados foram os registros do prontuário da família do usuário, os relatos descritivos dos atendimentos realizados e os genogramas dos usuários realizados pela pesquisadora. 0 roteiro de orientação para a coleta de dados utilizou como temáticas: Quem é a usuária que buscou atendimento psicológico? Como chegou até o atendimento psicológico? Qual o motivo da busca por atendimento psicológico? Existia uma demanda com foco na violência? Como a situação de violência foi trazida ao atendimento? Qual o significado atribuído à experiência de violência? Quais foram os desfechos subjetivos e os encaminhamentos depois da situação de violência? Qual a estrutura, a configuração e os vínculos familiares da usuária?

A análise e a discussão dos dados foram realizadas conforme orientações de Yin (2001) por meio de descrição do caso, criação de uma matriz de categorias emergentes e da discussão com as proposições teóricas que embasaram o estudo.

A fim de atender a Resolução n. 196/96 do Conselho Nacional de Saúde foi assinado o Termo de Compromisso para utilização de dados após aprovação do projeto no Comitê de Ética em Pesquisa da PUCRS e no Comitê de Ética em Pesquisa da Secretaria Municipal de Saúde de Porto Alegre.

\section{Resultados}

Os relatos aqui apresentados são baseados em atendimentos individuais utilizando-se como técnica a psicoterapia de apoio (Cordioli, 2008). Os resultados mostram um número expressivo de faltas durante o tratamento e mesmo o seu abandono. Conforme objetivos do estudo, o eixo central das vinhetas dos casos relatados foram os aspectos da violência trabalhados nos atendimentos; contudo, 
outras demandas e outros encaminhamentos foram dados para cada caso específico.

Vinhetas dos casos

\section{Caso A}

$A$ tem 28 anos, mora sozinha e trabalha como comerciante autônoma. Comunicou a agente comunitária de saúde que precisava de atendimento psicológico porque estava ambivalente na escolha do atual companheiro e isso estava dificultando a relação. Desde o primeiro atendimento, no relato da história de vida, referiu que quando criança foi abusada sexualmente pelo pai - "tenho nojo, vergonha quando lembro que ele dizia 'olha o que te fez', mas hoje tento perdoá-lo" e descreveu as cenas que visualizava da mãe "fazendo programas" com outros homens na sua casa quando seu pai viajava a trabalho.

Ela é a filha mais velha de quatro filhos; um dos irmãos, fruto da relação que mãe teve com um vizinho, é portador de uma deficiência. Aos 12 anos saiu de casa e passou a trabalhar como doméstica na casa de uma família no interior do estado. Aos 18 , casou-se com um homem quase 30 anos mais velho, com o qual permaneceu casada por quatro anos. Seu segundo relacionamento também foi com um homem mais velho e durou cerca de dois anos e meio. 0 último relacionamento, que já durava 18 meses, era com homem que conhecera por intermédio de uma amiga. Ela relatou que a relação foi marcada desde o primeiro encontro por momentos alternados de afeto e violência. Sua principal angústia era a dificuldade de conseguir tomar uma decisão diante daquele relacionamento.

$A$ referiu a irmã mais nova, 21 anos, como referência de apoio e como modelo de alguém com mais atitude e poder de decisão. Do restante da família, ela mantinha distância física, já que vivia há dez anos na capital. Mesmo existindo demanda de encaminhamento para psicoterapia, a paciente demonstrou-se resistente. A violência sempre foi um tema explícito nos atendimentos; contudo, esse não foi o motivo do atendimento psicológico; sua principal queixa era a incerteza quanto ao sentimento e à continuidade de seu relacionamento.

As situações de violência de natureza física, sexual, psicológica e negligência de cuidado vivenciadas pela paciente foram relatadas desde o primeiro atendimento e faziam parte da sua vida desde a infância. Dessa forma, percebeu-se o significado da experiência de violência como parte da sua história e da construção de sua identidade, parecendo não se conhecer sem violência.

\section{Caso B}

B, 21 anos, gestante, ensino médio completo, trabalha com a mãe e mora com os pais. Tem dois irmãos mais velhos que são casados. A mãe é aposentada e trabalha como cuidadora. 0 pai também é aposentado e tem um bar. Ela foi encaminhada para atendimento psicológico pela médica da unidade após primeira consulta pré-natal. A solicitação inicial era de avaliação psicológica já que a paciente apresentou-se muito chorosa e com resultado do teste de glicemia muito baixo, relatando que estava há quatro dias sem comer.

No momento da avaliação verificou-se a demanda para psicoterapia de apoio com objetivo de auxiliá-la a lidar com situação de crise e sofrimento devido ao término da relação de quatro anos com companheiro no início da gestação. Durante os atendimentos referiu ter apoio de família e amigos, sentindo-se acolhida por estes, mas enfatizou "fui deixada pelo meu noivo, agora que estou grávida ninguém vai me querer, nunca fiquei um mês sem ninguém, depois que nascer sei que vou encontrar alguém, daí não me preocupo".

Passou a se alimentar melhor, mas apresentava constantes desmaios, palpitações e não falava do filho que gestava. Após dois meses de atendimentos, trouxe a notícia de que seria mãe de uma menina e no mesmo atendimento disse ter "sonhado pesadelos", descrevendo cenas em que não deixava o seu pai segurar a sua filha. Seguida de uma intervenção interrogativa, a paciente associou seus sonhos com situação de abuso sexual perpetrado por seu pai durante sua adolescência. Ela relatou que ainda percebia seu pai a olhando quando se vestia, e esse motivo a fez dormir no quarto da mãe até três anos antes do tratamento.

Ela explicou que seus pais dormiam em quartos separados há muitos anos devido ao alcoolismo do pai, que costumava ser agressivo com toda a família. Relembrou agressões verbais em que ela e sua mãe eram chamadas de "cafetinas". A paciente acredita que o pai é uma pessoa de convivência agradável quando

Psicol. Argum. 2013 jul./set., 31 (74), 437-446 
não está sob efeito de álcool e que esses comportamentos ocorrem somente quando ele está alcoolizado "as besteiras que meu pai faz quando tá bêbado".

$B$ relatou ainda o receio quanto ao constrangimento que pode vir a ocorrer na família caso não permita seu pai segurar a sua filha. Nos atendimentos seguintes trouxe novas demandas como a relação com o ex-companheiro, a necessidade de processá-lo juridicamente, o uso de medicamento antidepressivo prescrito por médica, um novo relacionamento via internet e a ansiedade e o medo de sentir dor no parto.

A situação de violência raramente foi abordada novamente, expressando assim, a dificuldade de atribuir um significado a essa experiência. No entanto, a violência se repete nas suas demandas, nos seus sintomas ansiogênicos e suas relações, incluindo a relação com a filha recém-nascida, a qual descreveu como "bem careca coitadinha, parece o pai, mas a boca é minha". Ainda pode-se identificar a dificuldade de vinculação com a filha na evitação de amamentar: "tentei dar, mas não saiu leite e agora não sai mais nada". Logo após nascimento da filha, iniciou relacionamento com homem de 31 anos que trabalhava como segurança, tinha diagnóstico de epilepsia refratária e estava morando com ela na casa da sua família. É válido ressaltar que a situação de violência não foi o motivo da busca por atendimento psicológico e somente foi relatada após estabelecimento de vínculo com a terapeuta.

\section{Caso C}

C, 24 anos, ensino médio completo, trabalha como operadora de telemarketing, tem uma filha de 4 anos e está gestante do segundo filho. Ora mora na casa dos pais, ora na casa do companheiro, com quem havia rompido o relacionamento no início da gestação; esse rompimento causou sofrimento, o qual foi percebido pelo enfermeiro da unidade de saúde durante consulta de pré-natal, levando-o a encaminhá-la para a psicologia.

A paciente tem história de depressão na primeira gestação e, por essa razão, lhe fora prescrito antidepressivo novamente. Estava vivenciando momento de crise com companheiro com quem tem uma relação de oito anos. Haviam se separado devido ao cotidiano de muitas brigas. Ela trabalhava como secretária do companheiro em empresa própria e as brigas eram constantes no trabalho e em casa. Contudo, ela relatou que engravidou em um encontro de "recaída" e atualmente estava separada do companheiro, o qual se mostrou distante inclusive da função paterna. $C$ chorava ao mencionar que não estava acontecendo o que tinha sonhado para sua vida, ser mãe de duas crianças sozinha, voltar a morar na casa dos pais. Ela já havia passado por outros rompimentos; em um deles, quatro anos antes, ela engravidou da sua primeira filha e quem assumiu a função paterna foi o seu último companheiro.

Ela acreditava que seria difícil retomar a relação, pois o companheiro, segundo ela, "tem pensamento de ignorante", entendendo a mulher como submissa ao homem. Em muitos atendimentos analisou sua situação com o companheiro, sem deixar de trazer as preocupações com seus filhos. $C$ explicou que a filha está aceitando bem sua gestação e costuma demonstrar carinho pelo irmão. No entanto, após quatro meses de atendimentos, passou a reportar o comportamento da filha. Afirmou que a menina estava mais sensível, e chorava frequentemente. Ela associou o comportamento com a proximidade do nascimento do irmão e ao mesmo tempo levantou a hipótese de sua filha estar sofrendo abuso. Quando questionada sobre essa suspeita, ela mencionou uma situação de violência que vivenciou com a mesma idade da filha, perpetrada por um tio. Ela lembrou que o abuso sexual não teve penetração porque sua mãe entrou na sala antes que o fato acontecesse e não percebeu a situação. Ela assegurou que nunca havia contado essa história para ninguém porque nunca sentiu isso interferindo na sua vida, nem na vida sexual: "isso nunca me atrapalhou em nada, mas eu nunca esqueci". Ela relacionou a filha com a situação de violência vivenciada porque na o referido tio estava casado com uma de suas amigas e o filho do casal era o melhor amigo da menina.

Ela mencionou que a filha nunca trouxe nenhuma queixa e por isso não quis privá-la da convivência com o amigo. A paciente levantou questionamentos sobre sinais de abuso e solicitou orientações para melhor proteger a filha. Percebeu-se que a experiência de violência da paciente somente pode ser significada mostrando um padrão de comportamento não protetivo à filha, expondo a garota à figura do abusador. É possível visualizar a marca da violência na contradição "isso nunca me atrapalhou em nada, mas eu nunca esqueci". Dessa forma, a violência vivenciada tem como desfecho a dúvida de como cuidar dos filhos já que revive seu passado de cuidado. 


\section{Caso D}

$D, 15$ anos, estudante do ensino médio, mora com a família. Foi encaminhada para atendimento psicológico pela médica da unidade de saúde que, juntamente com a paciente, identificou a demanda devido a sofrimento e reprodução da violência vivenciada. Sua queixa inicial eram dores de cabeça, logo associadas com a violência intrafamiliar vivenciada por ela, pela irmã de 22 anos e pela mãe na convivência com o pai.

O pai era segurança aposentado, possuía arma de fogo em casa, fazia uso abusivo de álcool e tinha diagnóstico de esquizofrenia paranoide sem tratamento. A situação de violência foi reportada no atendimento médico após o pai ter se retirado da consulta; a paciente relatou chorando que o pai a proibia de sair de casa sozinha, a acompanha no trajeto da escola todos os dias, não permitia que tivesse namorado e a ameaçava de expulsá-la de casa se viesse a namorar. A adolescente explicou que era habitual o pai andar sem roupa pela casa e ter comportamento agressivo de beliscar quando contrariado e a assediar sexualmente - "passa a mão em mim".

Ela explicou que a violência intrafamiliar ocorria há 30 anos, desde o casamento dos pais, como se sempre tivesse vivenciado a situação. Ela mencionou que seus pais não dormem juntos desde que ela nasceu. Esclareceu que a mãe já registrou ocorrência de violência doméstica na delegacia, mas retirou a queixa por medo de mais violência.

A paciente tinha relação conflituosa com a irmã; percebe-se rivalidade entre elas. Segundo $D$, o pai tinha relação conflituosa com vizinhos e seus familiares reconheciam a possibilidade do transtorno mental, mas se diziam impotentes porque sabiam que ele não aceitaria tratamento. Depois de muitas tentativas, a mãe acompanhou a filha em atendimento e reiterou as agressões, "a loucura do marido" e o desejo de se separar. Em meio a isso, salientam-se sintomas de ansiedade e depressão decorrentes da ambivalência da mãe diante da situação de violência familiar; ela referiu que o motivo para não se separar seria o fato de o marido não ter outra casa para morar.

A família foi orientada e encaminhada a diversas medidas de proteção na rede como Conselho Tutelar, Centro de Referência de Atendimento a Crianças e Adolescentes vítimas de violência (CRAI), Delegacia da Mulher e também para tratamento em interconsulta na Saúde Mental. Pode-se pensar na hipótese de a paciente significar a violência como algo que está naturalmente na sua vida, já que seus vínculos são experimentados nesses formatos. Sua saída parece ser viver, transferir e transformar a violência que sofre nas relações com os outros.

\section{Discussão}

A violência pode ser observada nos casos descritos como um território secreto, do não dito, envolvendo questões de sigilo nas relações familiares e na psicoterapia. Nenhum dos casos buscou atendimento psicológico pelo motivo direto da violência; no entanto, a paciente $\mathrm{D}$ apresenta uma demanda inicial que se aproxima da sua experiência de violência. 0 estudo de Sant'Anna e Baima (2008) também mostra que os usuários chegam à psicoterapia por outras demandas $\mathrm{e}$ somente após consolidação do vínculo revelam a situação de violência, ou seja, na fase intermediária do tratamento. Isso pode ser observado nos casos de $B$ e $C$, que, com o vínculo terapêutico construído e após trabalharem a demanda inicial do sofrimento pelo rompimento com companheiro durante início da gestação, conseguiram relatar suas vivências de abuso intrafamiliar. Furniss (2001) reforça que revelar uma experiência de violência torna-se mais difícil quando esta ocorre dentro da família. Entende-se essa dificuldade quando se considera a família o principal contexto de desenvolvimento do ser humano, pois ocorrem as trocas, as inter-relações, o afeto, o compartilhar, a alternância de poderes e papéis (Bronfenbrenner, 1996).

A partir dos dados trabalhados, percebeu-se a dificuldade de revelar a violência intrafamiliar; contudo, pode-se pensar que a dificuldade é ainda maior quando a violência é vivenciada desde a infância. $\mathrm{Na}$ pesquisa de Numhauser e Soto (2006) sobre atendimento de mulheres vítimas de incesto, constatou-se que a média de idade da violência foi aos 10,6 anos e o tempo de revelar o incesto teve uma média de 17 anos depois, variando da revelação imediata até 50 anos após o ocorrido. A literatura reforça que o abuso na infância costuma ser ocultado por muitos anos tanto pelo pacto de silêncio familiar como pela dificuldade que a sociedade tem de perceber e denunciar a situação (Drezzet et al., 2001; Furniss, 2001; Narvaz \& Koller, 2004).

A violência não é referida em nenhum espaço, a pessoa não consegue atribuir significado, ao mesmo tempo em que não se reconhece sem a violência.

Psicol. Argum. 2013 jul./set., 31 (74), 437-446 
Os relatos das situações de violência foram contextualizados com falas que relacionaram as questões de segredo. Em alguns momentos, a violência é reconhecida, mas colocada em aspectos externos como o álcool "as besteiras que meu pai faz quando está bêbado" (caso B). No estudo de Wilhelm e Tonet (2007) sobre a percepção das mulheres que vivenciaram a violência doméstica também se identificou que todas as mulheres relacionaram as agressões aos momentos em que os companheiros estavam alcoolizados, tirando deles a responsabilidade sobre o ocorrido, com a justificativa de que estavam sob efeito de álcool.

A impossibilidade de dar significado à vivência de violência também foi encontrada no estudo de Schraiber et al. (2003), no qual 63,4\% das mulheres entrevistadas em uma unidade básica de saúde referem ter vivido algum tipo de humilhação, desrespeito, agressão física e sexual na vida adulta; contudo essas mulheres não nomeiam o vivido como violência. Esse distanciamento entre o vivido, a nomeação e a percepção da situação de violência perpassam a subjetividade de cada mulher.

A violência sem significado interno provocou marcas que não puderam ser elaboradas psiquicamente; nas mulheres estudadas, isso ficou evidenciado nas relações interpessoais posteriores, uma vez que a violência estava na construção de novas relações. As vivências da violência foram comparadas com outras situações difíceis da vida como o abandono do companheiro (casos B e C) e a proibição de sair para namorar (caso D); dessa forma, os conflitos atuais tornam-se prioridades e a violência permanece inerente à vida. As participantes não demonstraram entender esses eventos como violência em si, elas percebem a intensidade psíquica que permaneceu nessas experiências e deslocam esse excesso para um caminho que perpetua a violência, deixando marcas nos aspectos intrapsíquicos e sociais. Isso corrobora com outros estudos sobre esse tema (Schraiber et al., 2003; Narvaz, 2001; De Antoni \& Koller, 2000).

Mesmo sem nomear, a maioria das mulheres reconhece a vivência da violência como algo que não é certo, que traz sofrimento e não desejam tal situação; no entanto, a contradição foi observada na representação da violência como parte da vida (Schraiber et al., 2003)., o que pode ser entendido como um dos desfechos subjetivos que levam a perpetuação da violência nas relações atuais, principalmente no caso A.

Pensando nos casos de violência desde a infância, percebe-se violência como algo horizontal, ou seja, são experiências marcantes que acompanham a pessoa ao longo da vida. Por outro lado, existem outras vivências que podem ser caracterizadas como verticais, pois acontecem no cotidiano de cada pessoa e acabam dando sentido e reiterando a horizontalidade da violência na vida. De acordo com Narvaz (2001), a violência internalizada desde a infância juntamente com um modelo de interação familiar não protetivo caracteriza a transgeracionalidade da violência já que essas mulheres não aprenderam a se proteger nem a proteger seus filhos. Isso pode ser exemplificado pelo caso $\mathrm{C}$, em que a filha de 4 anos é exposta ao mesmo abusador da mãe. Por meio dos genogramas construídos durante os atendimentos, pode-se observar que em todas as famílias os vínculos foram qualificados como violentos. Ainda segundo Narvaz (2001), para sair da repetição é preciso trabalhar e conectar as mulheres, mães não protetivas, com as suas próprias histórias de violência e proporcionar novos modelos de relações com padrões mais protetivos.

A psicoterapia foi um recurso disponibilizado pela rede de saúde que ampliou o acesso ao cuidado, já que as mulheres do estudo não encontraram nos seus sistemas familiares possibilidades de saúde e de proteção. Schraiber et al. (2003) ressaltam que um dos desafios da mulher que chega a um serviço de saúde é cuidar do sofrimento provindo da situação de violência e este não ser transformado pelos profissionais em depressões ou ansiedades, para assim, ser acolhida sem a linguagem da doença. Para Bronfenbrenner (1996), a família envolvida em situação de violência precisa ser vista com os seus potenciais para o desenvolvimento. Assim, para os profissionais realizarem uma intervenção efetiva é preciso conhecer a rede da família, a parte social e afetiva, os recursos disponíveis e suas funções, as crenças e valores sobre violência em todos os níveis, desde a família até a comunidade e sociedade na qual estão inseridos.

Esse enfoque acompanhou os atendimentos da presente pesquisa, entendendo-se que a escuta do fenômeno da violência precisa ser ampliada para além da queixa apresentada inicialmente. Para as usuárias deste estudo foi oferecido suporte psicológico tendo diferentes desfechos, dentre eles, a percepção da psicoterapia como recurso de apoio, como movimento de aproximação aos atos violentos ou como um meio de adquirir benefícios secundários. 0 tempo do tratamento psicológico variou 
de um a dois meses nos casos de abandono do tratamento (casos A e D) e de oito a nove meses nos casos que tiveram seguimento na psicoterapia de apoio (casos B e C).

Acredita-se que é necessário proporcionar um modelo de relação com padrões mais protetivos para a intervenção por meio de uma escuta não ameaçadora, de modo a compreender a vivência da violência no contexto que foi apreendida e aprendida para que possa ser desconstruída a repetição, a perpetuação ou a transmissão transgeracional da violência (Narvaz, 2001). Pode-se observar que em alguns momentos a psicoterapia serviu como lugar de revivência das questões da violência, pois o apoio levou a faltas e ao abandono de tratamento. No entanto, a psicoterapia também serviu como dispositivo de superação da situação de violência, quebrando a perpetuação e apresentando um novo modelo de se relacionar.

\section{Considerações finais}

A violência está dentro de um território velado, do pouco falado nas equipes de saúde e, inclusive, na psicoterapia. A experiência de violência não foi o motivo da busca de atendimento nas unidades de saúde, sendo referenciada na psicoterapia como mais uma dificuldade da vida. Contudo, essa dificuldade vinda da infância deixou marcas que não foram elaboradas até a vida adulta. Possivelmente por essa falta de simbolização e transformação das vivências traumáticas, as usuárias seguiram atualizando a violência nas suas novas relações, ou seja, como repercussão subjetiva tem-se a perpetuação da violência.

Nesse sentido, pode-se pensar que esses foram quatro casos que tiveram acesso a um modelo mais protetivo e que foram analisados em profundidade; no entanto, sabe-se que há muitos outros casos de violência que passam nas unidades de saúde todos os dias. Portanto, questiona-se como tornar a rede de saúde uma rede mais articulada para apoio à situação de violência intrafamiliar. Baseado nesse estudo, ressalta-se a importância de toda a rede compreender o significado e como os usuários vivenciam a experiência da violência intrafamiliar.

A psicoterapia foi um recurso da rede dessas usuárias, podendo ser considerada uma forma de apoio que auxilia na proteção psíquica, o lado interno que precisa ser cuidado. Contudo, os cuidados externos da rede também são fundamentais tais como acolhimento e avaliação das situações de violência na atenção primária, atendimentos em ambulatórios especializados para profilaxias, abrigos que visam proteção imediata, serviços de atendimentos jurídicos, assistenciais e psicológicos entre tantos outros. A rede precisa estar interligada para contemplar todo o cuidado que necessita uma situação de violência, e ir além, contribuindo para a prevenção da violência e assim, fortalecer os aspectos de promoção da saúde.

\section{Referências}

Brasil (2002). Ministério da Saúde. Secretaria de Políticas de Saúde. Violência Intrafamiliar: Orientações para a prática em serviços. Brasília: Ministério da Saúde.

Bronfenbrenner, U. (1996). A ecologia do desenvolvimento humano: Experimentos naturais e planejados. Porto Alegre: Artes Médicas. (Obra originalmente publicada em 1979).

Cordioli, A. (2008). Psicoterapias: Abordagens atuais. Porto Alegre: Artmed.

De Antoni, C., \& Koller, S. H. (2000). A visão sobre família entre as adolescentes que sofreram violência intrafamiliar. Estudos de Psicologia, 5(2), 347-381.

Drezzet J. F., Cabalero, M., Juliano, Y., Prieto, E. T., Marques, J. A., \& Fernandes, C. E. (2001). Estudo de mecanismos e fatores relacionados com o abuso sexual em crianças e adolescentes do sexo feminino. Jornal de Pediatria, 77(5), 413-419.

Furniss, T. (2001). Abuso Sexual da criança: Uma abordagem multidisciplinar. Porto Alegre: Artes Médicas.

Gomes, R., Silva, C. M. F. P., \& Njaine, K. (1999). Prevenção à violência contra a criança e o adolescente sob a ótica da saúde: Um estudo bibliográfico. Ciência e Saúde Coletiva, 4(1), 171-181.

Gomes, R., Almeida, A. B. B., Ecteins, I. B., Solter, M., \& Paiva, S. C. S. (1999). A saúde e direito da criança ameaçados pela violência. Revista Latino Americana de Enfermagem, 7(3), p.5-8.

Martins, C. B. G., \& Mello Jorge, M. H. P. (2009). Desfecho dos casos de violência contra crianças e adolescentes no poder judiciário. Acta Paulista de Enfermagem, 22(6), 800-807.

Psicol. Argum. 2013 jul./set., 31 (74), 437-446 
Meneghel, S. N., Camargo, M., Fasolo, L. R., Mattiello, D. A., Silva, R. C. R., Santos, T. C. B., Dagord, A. L., Reck, A., Zanette, L., Sotteli, M., \& Teixeira, M. A. (2000). Mulheres cuidando de mulheres: Um estudo sobre a Casa de Apoio Viva Maria, Porto Alegre, Rio Grande do Sul, Brasil. Cadernos de Saúde Pública, 3(16), 747-757.

Milani, R. G., \& Loureiro, S. R. (2008). Famílias e violência doméstica: Condições psicossociais pós ações do Conselho Tutelar. Psicologia: Ciência e Profissão, 28(1), 50-67.

Minayo, M. C. S. (2006). Violência e saúde. Rio de Janeiro: Fiocruz.

Moura, A. T. M. S., \& Reichenheim, M. E. (2005). Estamos realmente detectando a violência familiar contra a criança em serviços de saúde? A experiência de um serviço público do Rio de Janeiro, Brasil. Cadernos de Saúde Pública, 21(4), 1124-1133.

Narvaz, M. G. (2001). A transmissão transgeracional da violência. Insight, 11(118), 17-22.

Narvaz, M. G., \& Koller, S. H. (2004). Famílias, gênero e violências: desvelando as tramas da transmissão transgeracional da violência de gênero. In M. N. Strey, M. P. R. Azambuja \& F. P. Jaeger (Org.). Violência, gênero e políticas públicas. (pp. 149-176). Porto Alegre: EdiPUCRS.

Numhauser, J., \& Soto, P. (2006). Consejos en la psicoterapia de mujeres víctimas de incesto: Revisión de 59 casos. Revista Chilena de Neuro-Psiquiatria, 44(4), 271-281.
Organização Mundial da Saúde [OMS]. (2002). Relatório mundial sobre violência e saúde. Genebra: Organização Mundial da Saúde.

Padovani, R. C., \& Williams, L.C.A. (2002). Intervenção psicoterapêutico com o agressor conjugal: Um estudo de caso. Psicologia em Estudo, 7(2), 13-17.

Reichenheim, M. E., Hasselmann, M. H., \& Moraes, C. L. (1999). Conseqüências da violência familiar na saúde da criança e do adolescente: Contribuições para a elaboração de propostas de ação. Ciência e Saúde Coletiva, 4(1), 109-121.

Ríos, J. A. G. (1991). Manual de orientación y terapia familiar. Madrid: Instituto de Ciencias del Hombre.

Sant'Anna, P. A., \& Baima, A. P. S. (2008). Indicadores clínicos em psicoterapia com mulheres vítimas de abuso sexual. Psicologia: Ciência e Profissão, 28(4), 728-741.

Schraiber, L. B., Oliveira, A. F., \& Couto, M. (2006). Violência e Saúde: Estudos científicos recentes. Revista de Saúde Pública, 40(esp.), 112-120.

Schraiber, L. B., Oliveira, A. F., Hanada, H., Figueiredo, W., Couto, M., Kiss, L., Durand. J., \& Pinho, A. (2003). Violência vivida: A dor que não tem nome. Interface: Comunicação, Saúde, Educação, 7(12), 41-54.

Wilhelm, F., \& Tonet, J. (2007). Percepção sobre a violência doméstica na perspectiva de mulheres vitimadas. Psicologia Argumento, 25(51), 401-412.

Yin, R. K. (2001). Estudo de Caso: Planejamentos e métodos (2. ed.). Porto Alegre: Bookman. 